\title{
A modo de contrarréplica: la ignorancia deliberada y su difícil encaje en la teoría dominante de la imputación subjetiva
}

Ramon Ragués i Vallès

\section{Introducción}

Antes de dar respuesta a los cuatro trabajos que preceden a estas páginas de réplica final debo expresar mi sincera gratitud a los queridos colegas María Laura Manrique, Bernardo Feijoo, Luis Greco y Alberto Puppo por sus interesantes observaciones y propuestas, así como también por sus objeciones y críticas. Que estos cuatro admirados académicos hayan dedicado su valioso tiempo a reflexionar y escribir sobre mi trabajo representa un inmenso honor. Mi gratitud también a los editores, por invitarme a participar en una publicación con un formato tan sumamente adecuado para la discusión científica. Aunque en los ambientes académicos los debates son algo habitual, el tempo de la discusión rara vez es el adecuado: en los seminarios las preguntas y las respuestas suelen formularse sin la reflexión y la precisión necesarias; y en la literatura los comentarios a menudo no llegan hasta que otro colega escribe sobre el mismo tema, lo que muchas veces no sucede hasta años más tarde, cuando el destinatario de las observaciones ya anda interesado en otros asuntos. Discusiones hace posible replicar con proximidad temporal y, al mismo tiempo, con la precisión y reflexión que solo el texto escrito proporciona. Además, permite que el debate vaya mucho más allá de la sala de seminarios o de unas notas al pie permitiendo que otras personas disfruten del intercambio de opiniones. Se trata de una singular contribución al debate académico que supone un estimulante reto para el autor invitado. 
Como el lector habrá podido advertir, los cuatro trabajos previos coinciden en algunas de sus observaciones y difieren en otras. De ahí que, para dar respuesta a los cuatro textos en un número razonable de páginas, lo que parece más adecuado es agrupar la respuesta a aquellas observaciones en las que existe coincidencia entre los autores, procediendo, cuando sea necesario, a responder de manera particular a aquellos comentarios u objeciones que se hayan formulado solo a título individual. Dado que en el momento de redactar estas líneas aún no es posible conocer la paginación final del presente volumen, las referencias a pasajes concretos de los cuatro textos previos se realizarán citando el número de cada apartado.

\section{II. ¿Tiene un sentido propio la ignorancia deliberada?}

\section{II.1. Una doctrina en gran medida innecesaria en los sistemas continentales}

De la ignorancia deliberada lo primero que se cuestiona es la posibilidad de su propia existencia en tanto que, por así decirlo, hecho psíquico o estado mental: "si se tiene intención de ignorar es porque, en realidad, se sabe lo que se ignora", dice el Tribunal Supremo español en una sentencia ya citada supra (IV.1) y en una afirmación que comparte Bernardo Feijoo (I.2. nota 9$)^{1}$. Sin embargo, los sencillos ejemplos expuestos al principio del texto inicial muestran que la decisión de no profundizar o no perfeccionar los conocimientos básicos con los que cuenta una persona es una forma de comportarse no precisamente infrecuente en la vida cotidiana: en modo alguno resulta extraño o incomprensible decir que alguien, por ejemplo, "no ha querido confirmar sus sospechas" respecto de una posibilidad que le resultaba desagradable.

Ciertamente, una situación cuya concurrencia parece improbable -y seguramente en la que estaba pensando el Tribunal Supremo

1 También Pérez BArberÁ, El dolo eventual, Buenos Aires, 2011, p. 799 (nota 387) coincide en que "si hay completa falta de representación no es imaginable una deliberación para ignorar". 
A modo de contrarréplica: la ignorancia deliberada y su difícil encaje ...

español en la citada resolución- es aquélla en la que el sujeto evita deliberadamente conocer aquello que ni tan siquiera ha llegado a sospechar que pueda existir. Sin duda, debe coincidirse con la Sala Segunda en que nadie puede pretender evitar la adquisición de conocimientos sobre una realidad que ni tan siquiera sospecha que existe ${ }^{2}$; pero sí que se dan situaciones en las que un sujeto es consciente del potencial lesivo más o menos determinado de su conducta -u omisión- y prefiere no hacer el esfuerzo necesario para precisar exactamente en qué consiste dicha lesividad y cuáles son las características cualitativas, cuantitativas o temporales del riesgo creado. Para poder efectuar las necesarias precisiones parece adecuado distinguir entre tres situaciones posibles que, para una mejor comprensión, se expondrán de la mano de los siguientes ejemplos:

$1 .^{\circ}$ A recibe un mensaje de correo electrónico de un juzgado que lleva por título "notificación oficial"3. Dado que sospecha que puede tratarse de un requerimiento de información que espera desde hace tiempo, pero no quiere cumplimentar, decide borrar el mensaje-que contenía efectivamente un requerimiento de información- sin llegar a abrirlo siquiera.

2. ${ }^{\circ}$ A recibe un mensaje de correo electrónico de un juzgado que lleva por título "notificación oficial". A sospecha que puede tratarse de varias cosas que le desagradan: un requerimiento de información, una citación a declarar como testigo o una sentencia que le conde-

2 Se coincide en este punto, aunque con matices, con Alberto Puppo cuando señala (III.A) que "si no conozco los hechos a los cuales el derecho penal imputa consecuencias penales, no puedo decidir ignorarlos para evitar tales consecuencias". En determinadas situaciones de desconocimiento provocado la representación de la que parte el sujeto no supone un conocimiento en el sentido fuerte de la expresión, sino una sospecha -incluso leve- de que una determinada circunstancia, presente o futura, puede llegar a concurrir.

3 Ciertamente el ejemplo puede sorprender a quienes en 2014 vivan en lugares en los que las administraciones aún prefieran comunicarse por escrito con los ciudadanos. Pero cabe imaginar perfectamente que el correo electrónico sea en el futuro la vía habitual de comunicación como ya lo es en España, por ejemplo, para ciertos trámites. 
na a privación del permiso de conducir. Para no confirmar sus sospechas prefiere borrar el mensaje, que contenía un requerimiento judicial de información que queda sin cumplimentar.

3. A piensa que de la administración nunca puede llegar ninguna noticia agradable. Por ello, cuando instala su programa de correo electrónico incluye la dirección de los organismos públicos en una lista de "correo basura" que suprime directamente los mensajes que se reciban con dicho origen. Por este motivo, cuatro años más tarde ignora que se le ha enviado un requerimiento de información de un juzgado, una petición que obviamente no cumplimenta.

De manera indiferenciada la jurisprudencia española (cfr. mi artículo inicial IV.1) aplica la teoría de la ignorancia deliberada a casos que presentan la estructura de las tres situaciones descritas, aun cuando en los casos primero y segundo dicha doctrina no sea estrictamente necesaria si lo que se pretende es condenar por un delito de desobediencia en su modalidad dolosa ${ }^{4}$. De hecho, un punto en el que existe amplio consenso entre los anteriores colegas es en la constatación de que muchos de los supuestos que habitualmente se han tratado por la jurisprudencia bajo la denominación de ignorancia deliberada son, en realidad, casos que, de acuerdo con el sistema de imputación subjetiva más extendido en el ámbito continental, son de auténtico dolo eventual y, por ello, no existe ninguna necesidad de recurrir a esta doctrina anglosajona para darles la respuesta jurídica prevista para el dolo (en tal sentido, por ejemplo, Feijoo I.1 in fine o Greco 1). Así, tanto en el supuesto $1 .^{\circ}$ como en el $2 .^{\circ}$ el sujeto es consciente del riesgo -o de la probabilidad- de que el mensaje que destruye contenga un requerimiento judicial de informa-

${ }^{4}$ Se partirá aquí de la premisa según la cual desatender con dolo requerimientos judiciales da lugar al citado delito de desobediencia. Es posible que en algunos lugares para aplicar la citada infracción no baste con una única desatención y sea necesario -como suele exigir la jurisprudencia españolaque el sujeto se niegue reiteradamente a responder. Tal opción interpretativa no resta sentido a los ejemplos: piénsese simplemente en que la ausencia de respuesta no se produce una sola vez sino tras varias notificaciones electrónicas en un mismo sentido. 
A modo de contrarréplica: la ignorancia deliberada y su difícil encaje ...

ción y, en consecuencia, concurre dolo eventual del delito de desobediencia si se admite que la representación del riesgo basta para esta modalidad de imputación subjetiva. De manera más concreta, en el primer caso concurre dolo eventual sin más, mientras que el segundo es un caso de dolo eventual alternativo (el sujeto se representa como posibles varios desenlaces lesivos para el interés protegido y uno de ellos coincide con la realidad).

Tanto en el presente volumen como en otras publicaciones previas he tratado de poner en evidencia respecto de la jurisprudencia española que el "descubrimiento" de la teoría de la willful blindness a principios del presente siglo ha servido, en buena medida, para aligerar la carga de fundamentación jurídica en la prueba del elemento cognitivo del dolo, olvidando a menudo que la ignorancia deliberada también incluye un factor subjetivo -a saber, el carácter intencionado del desconocimiento- cuya prueba no debe de resultar precisamente menos compleja que la del propio conocimiento. Precisamente porque -como subraya Puppo (II)- la presunción de inocencia extiende también sus efectos al tipo subjetivo, probar que alguien sabía que llevaba drogas en una maleta requiere realizar un juicio de inferencia no menos complejo que el que requiere demostrar que dicha persona, que llevaba drogas, no fue consciente de tal circunstancia porque intencionadamente (es decir, no por descuido, olvido o imposibilidad material) evitó cerciorarse del contenido del recipiente.

Sin embargo, en la jurisprudencia española este último elemento suele pasarse por alto y en la aplicación judicial de esta doctrina el carácter deliberado del desconocimiento se infiere a menudo de la mera circunstancia de que el sujeto podia haber profundizado en ciertos conocimientos y no lo hizo, una forma de proceder que convierte en inviable cualquier distinción entre dolo y culpa pues también en este último caso es necesario que el sujeto pudiera conocer y no lo hiciera, pues de otro modo se vulneraría el principio de culpabilidad. Por citar un ejemplo: el conductor de autobús que nota que los frenos de su vehículo hacen un ruido extraño pero que, confiando en que todo irá bien, prefiere no detenerse cuando pasa ante un taller y provoca al poco rato un grave accidente mortal, también es un ignorante deliberado, porque ante sus sospechas de 
que algo funcionaba mal, ha optado por permanecer en el desconocimiento y renunciar a que el mecánico le aclarase la causa real de los extraños ruidos. No obstante, difícilmente alguien sostendría que, en un caso como éste, el sujeto merece ser castigado con la pena prevista para el homicidio doloso.

En muchos supuestos el recurso a esta doctrina es tan innecesario como poco recomendable por el evidente peligro de ampliación injustificada del ámbito de lo doloso, por la pérdida de criterios claros de diferenciación entre lo doloso y lo imprudente y porque, en la práctica, su uso ha ido acompañado de una evidente merma en la necesaria motivación de las razones por las que el juez considera que concurren los presupuestos fácticos que permite aplicar la figura del dolo ${ }^{5}$. Por ello se comparten plenamente las críticas que a propósito de la aplicación de esta doctrina por los tribunales españoles formula en su trabajo Bernardo Feijoo (I.3). A ellas cabría añadir, asimismo, el hecho de que en sus orígenes esta teoría fuera un criterio importado por la jurisprudencia española para dar respuesta, de modo casi exclusivo, a casos muy concretos de transporte de objetos relacionados con el blanqueo de capitales o el tráfico de drogas, en los que los tribunales suelen encontrarse con alegaciones de desconocimiento por parte de los acusados que no siempre es fácil desvirtuar con una motivación convincente. Cierto es, sin embargo, que en los últimos años su radio de acción se ha ampliado al Derecho penal económico-empresarial, aunque los términos de su aplicación en este ámbito sigan planteando dudas y disten mucho de ser uniformes ${ }^{6}$. Dicha ampliación, ciertamente, impide afirmar actualmente que esta doctrina sea solo un criterio de imputación buscado ad hoc para ciertos delitos (y delincuentes); pero su ampliación extiende las dudas que plantea esta teoría a otras modalidades de criminalidad.

5 Un resumen de las críticas que, a mi juicio, merece la doctrina de la Sala Segunda del Tribunal Supremo en Ragués I VALLÈs, La ignorancia deliberada, Barcelona, 2007, p. 210.

6 Ver en tal sentido mi reciente trabajo "La doctrina de la ignorancia deliberada y su aplicación al Derecho penal económico-empresarial", en SiLVA SÁnchez / Miró Llinares (dirs.), La teoría del delito en la práctica penal económica, Madrid, 2013, pp. 289-319. 
A modo de contrarréplica: la ignorancia deliberada y su difícil encaje ...

\section{II.2. La ignorancia deliberada en sentido estricto}

Dando por sentada la anterior conclusión -es decir: la mayoría de casos de ignorancia deliberada pueden ser de dolo eventual con una adecuada motivación de los juicios de inferencia ${ }^{7}$ - no necesariamente debe negarse todo sentido a esta categoría en los casos denominados de ignorancia deliberada en sentido estricto, ciertamente poco habituales en la práctica pero en modo alguno inexistentes. El mejor ejemplo de ello es el caso $3 .^{\circ}$ de los antes descritos, así como otros supuestos que se proponen en el texto inicial (apartado IV), entre los que puede traerse a colación de nuevo el supuesto no tan infrecuente del testaferro profesional que, a cambio de una remuneración, se presta a figurar como administrador formal de cientos de empresas sospechando que es posible que alguna de ellas se acabe utilizando por sus verdaderos administradores, en algún momento futuro indeterminado, para la comisión de algún delito de muy difícil previsión y concreción en el instante, muy anterior en el tiempo, en el que se asume formalmente el cargo.

Ciertamente cabe sostener, como se hace por ejemplo en el texto de Feijoo (I.1.), que en tal circunstancia este último sujeto obraría con una especie de "macrodolo eventual alternativo" que abarcaría la comisión de prácticamente cualquier posible infracción penal que pudiera llegar a cometerse con dicha sociedad. Sin embargo, tal afirmación plantea problemas de compatibilidad con el concepto más extendido de dolo, que exige que la representación lo sea del riesgo concreto generado y que, en el caso más específico de partícipes en hechos ajenos, como el testaferro, requiere para afirmar el dolo la representación de los rasgos esenciales del hecho principal del autor (las "circunstancias

7 De dolo eventual, cabe matizar, de acuerdo con el concepto de esta figura que defienden las teorías que consideran que concurre esta modalidad de dolo cuando el sujeto obra pese al conocimiento del riesgo de realización del tipo. Ciertamente, las premisas de las que se parte supra cambian si se acoge la perspectiva -no precisamente minoritaria- de que, además del elemento de representación, el dolo eventual requiere un componente de naturaleza volitiva (o pseudovolitiva), como el "aceptar", "conformarse" o "resignarse" con la producción del resultado lesivo. 
esenciales del hecho principal" o el "contenido esencial de la dirección del ataque", se sostiene en la STS 258/2007 citada por el propio Feijoo). De quien "es consciente de que se incorpora a una simulación organizada" no puede afirmarse sin más que conozca solo por ello las "circunstancias esenciales del hecho principal" que pueda llegar a cometerse en un futuro indeterminado.

No deja de resultar llamativo que, para evitar los riesgos que se asocian a la doctrina de la ignorancia deliberada, entre ellos el de ampliación injustificada de lo doloso, se recurra a una radical flexibilización del objeto del dolo ${ }^{8}$ Y en tal sentido llama la atención que el propio Feijoo cite a favor de su perspectiva la Sentencia del Tribunal Supremo español $234 / 2012$, en la que se sostiene que pueden tratarse como dolosos -a través de la doctrina de la ignorancia deliberada- casos en los que "la sospecha puede incluso no llegar a perfilar la representación de todos y cada uno de los elementos del tipo objetivo, al menos, con la nitidez exigida de ordinario para afirmar la concurrencia del elemento intelectual del dolo" (cursiva añadida). Como señala en su comentario Alberto Puppo (introducción), una sospecha inicial no es todavía conocimiento. $\mathrm{O}$, cabe añadir, no es el conocimiento cualificado que en la doctrina más extendida suele exigirse para diferenciar el dolo eventual de la culpa consciente por medio de expresiones como "tomar en serio", "representación del riesgo en concreto", "contar con" etc. ${ }^{9}$.

8 En tal sentido se coincide con Pérez BARBeré, El dolo eventual, p. 799 (nota 387) cuando señala este autor que "si hay 'algo' de representación pero solo de conductas típicas indeterminadas, entonces es correcto que no se impute dolo". Ciertamente tal coincidencia no pasa de este punto, pues este autor (ibidem) no admite que las razones que han impulsado al sujeto a no profundizar en su representación puedan convertir en doloso aquello que no lo es atendiendo al mero elemento cognitivo.

9 En tal sentido resulta interesante la diferenciación que realiza Alberto Puppo (II) entre sospechar, creer o aceptar. Puede discutirse si para considerar concurrente el elemento cognitivo del dolo el conocimiento del sujeto debe situarse más bien en el terreno de las creencias o de la aceptación. Pero en cualquier caso la mera sospecha, entendida como un conocimiento "espontáneo e incontrolado" parece que no debería bastar para el dolo de acuerdo con los planteamientos más extendidos. 
A modo de contrarréplica: la ignorancia deliberada y su difícil encaje ...

$\mathrm{Al}$ anterior problema se añade otro de naturaleza temporal en aquellos casos en los que el "ignorante deliberado" no es, como el testaferro, un partícipe que colabora con el futuro autor realizando una aportación anterior en el tiempo al hecho principal, sino que es directamente el autor del hecho objetivamente típico. A tal efecto cabe recordar que las teorías más extendidas acerca del tipo subjetivo requieren que la representación que exige el dolo se presente a la vez que se realiza el hecho objetivamente típico, quedando fuera del concepto jurídicopenal de dolo tanto el llamado dolus antecedens como el subsequens, es decir, aquellos casos en los que la representación (o intención) exigidos por el dolo se presentan, respectivamente, antes o después de la realización del hecho. Retomando el ejemplo anterior: imagínese el caso del individuo que ha decidido en 2007 que todas las notificaciones oficiales que reciba en el futuro vayan directamente a la lista de "correo basura" ipuede afirmarse que, cuando en 2014 no lea por tal motivo un requerimiento judicial, está representándose tal circunstancia? Responder afirmativamente a tal cuestión solo parece posible dando por buena una segunda flexibilización -en este caso temporaldel concepto de dolo más asentado.

Ciertamente una posibilidad para dispensar a estos ejemplos el tratamiento del dolo seria entender que para este título de imputación basta con obrar representándose que la conducta realizada es potencialmente lesiva para cualquier interés indeterminado protegido por el Código Penal. Y que, desde el punto de vista temporal, es suficiente para el dolo con que en algún momento el sujeto haya podido representarse que, con una acción u omisión propia futura, también absolutamente indeterminada, pueda acabar menoscabando algún objeto de protección. Sin embargo, aceptando tales posibilidades aun parecen asumirse más riesgos de desbordamiento del concepto de dolo que con la doctrina de la ignorancia deliberada, pues en la exigencia expresa de intencionalidad en la decisión del sujeto de ignorar esta teoría encuentra un límite para una ampliación muy sensible del ámbito de lo doloso. 


\section{II.3. Similitudes y diferencias con otras situaciones}

Señala Luis Greco en su trabajo que en los supuestos denominados de "ignorancia deliberada en sentido estricto" la infracción de la norma debe buscarse en el comportamiento previo, en el que el conocimiento por parte del acusado está todavía presente, actuando en el segundo momento el sujeto como una suerte de autor mediato que se instrumentaliza a sí mismo en situación de error. Se trata de una solución atractiva, a la que el autor sin embargo no atribuye curiosamente mucha relevancia práctica al señalar que "es casi inimaginable que ese autor no se acuerde de su previa actuación”, una afirmación que, sin embargo, desmiente el ejemplo antes expuesto de quien configura su programa de correo para que rechace notificaciones oficiales: una vez dispuesto el filtro de los mensajes, lo más lógico es que el sujeto solo esporádicamente recuerde su decisión y es perfectamente plausible que el día que ingrese en su servidor el concreto requerimiento judicial desatendido y durante los días de su vigencia no piense por un solo momento en tal posibilidad o que, en cualquier caso, la demostración procesal de una representación momentánea resulte sencillamente imposible.

Como señala el propio Greco, dicho ejemplo presenta alguna similitud con el caso de consumación diferida en el tiempo que concurre, por ejemplo, en el supuesto del sujeto que coloca una bomba de relojería que estallará horas más tarde sin que en el instante de la explosión dicho sujeto esté pensando en tal circunstancia. Sin embargo, existe una diferencia importante entre los dos supuestos: así, mientras en el caso de la colocación de la bomba concurre representación del riesgo durante una parte de la realización de la fase ejecutiva, en el caso del "correo basura" el sujeto cuenta con la representación exigida por el dolo (aceptando por bueno a efectos de dolo un conocimiento todavía muy indeterminado sobre un hipotético requerimiento futuro) cuando no ha surgido todavía el deber que acabará omitiendo, es decir, mucho antes de que pueda hablarse del inicio de la fase de tentativa y sin tener la certeza siquiera de si dicho deber acabará surgiendo algún día o de cuál será su contenido. 
A modo de contrarréplica: la ignorancia deliberada y su difícil encaje ...

La estructura de tales supuestos sí plantea-como advierte el propio Greco y han puesto de manifiestos otros autores-similitudes evidentes con los supuestos de actio libera in causa, en los que el sujeto provoca la ausencia de un elemento necesario para su responsabilidad (como la voluntariedad de la acción o la culpabilidad) con el propósito de llevar a cabo una conducta ilícita. Sin ir más lejos, en su monografía sobre la actio libera, Ujala Joshi contempla el error de tipo como una de las situaciones que cabe encuadrar en esta estructura de imputación, afirmando expresamente que "la provocación de un error de tipo presenta una estructura igual a la provocación de la inimputabilidad"10. Por su parte, Rafael Alcácer propone una definición amplia de la actio libera, que abarque "el conjunto de situaciones en las que un sujeto lesiona (o intenta lesionar) un bien jurídico en un estado o situación que impide la imputación de responsabilidad penal (en sentido amplio), pero habiendo provocado él mismo, dolosa o imprudentemente, ese estado defectuoso" "11. Según este último autor, de acuerdo con esta definición tan amplia, "podría, en principio, incluirse bajo la figura de la alic la provocación de cualquier forma de exclusión de responsabilidad penal, desde la provocación de una situación de ausencia de acción hasta la ausencia de imputabilidad, pasando por la provocación de un estado de justificación (actio illícita in causa), de una situación de necesidad exculpante, de un error de tipo o de prohibición o de una causa de inexigibilidad"12 (cursiva añadida).

Desde algunas perspectivas la traslación de esta estructura a los ca-

${ }^{10}$ Joshi Jubert, La doctrina de la "actio libera in causa" en Derecho penal, Barcelona, 1992, p. 87. El ejemplo que menciona esta autora (ibidem, pp. 83-84) es el de un ingeniero encargado de seguridad de la maquinaria de una industria que omite reparar el defecto técnico de una máquina que ha advertido pero que prefiere olvidar para dedicarse a otras cosas.

${ }^{11}$ Alcácer Guirao, Actio libera in causa dolosa e imprudente, Barcelona, 2004, p. 21.

${ }^{12}$ Alcácer Guirao, Actio libera, p. 22. Según este autor (ibidem, p. 23) "lo que caracteriza a la figura de la alic es esencialmente la particular estructura de que se compone" y, por tanto, "no habría, prima facie, obstáculos teóricos para acomodar esa estructura a cualquiera de las formas de exención de la responsabilidad penal, pudiendo admitirse una concepción amplia de la alic como expresión de un grupo de casos con una común estructura". 
sos de error de tipo puede plantear evidentes problemas de legalidad en aquellos ordenamientos -la totalidad de los que se conocen-que no han previsto excepción alguna para las situaciones de desconocimiento provocada: son los problemas ya conocidos con los que, de manera general, topa la doctrina de la actio libera allá donde la excepción que supone no está prevista en el texto de la ley. Sea como fuere, si se admite -con Greco- que la estructura de la actio libera puede aplicarse a estas situaciones y puede condenarse en tales casos por una conducta dolosa, en el fondo se está dando la razón a la teoría de la ignorancia deliberada al aceptarse que puede haber dolo sin que por parte del sujeto exista representación del tipo objetivo en el momento de llevar a cabo la acción u omisión penalmente relevante. Así, la teoría de la willful blindness no sería otra cosa que un caso particular de aplicación de dicha estructura de imputación -la actio libera in causa- al error como causa de exclusión del tipo subjetivo.

Tal posibilidad topa con los problemas clásicos de dicha teoría, pues, por lo menos en el planteamiento que se defiende de acuerdo con la llamada "solución o el modelo del tipo", obliga a sostener que en el momento en que el sujeto decide llevar a cabo las acciones que impedirán que le alcancen determinados conocimientos ya ha iniciado la ejecución delictiva. Aun aceptando tal interpretación, sin embargo, el problema más grave se da en aquellos casos en los que no existe una intención específicamente dirigida a evitar la información. En tal sentido, debe valorarse con suma cautela la aplicación automática de esta teoría al tipo subjetivo, pues la renuncia a la exigencia temporal en este ámbito -es decir, a la simultaneidad entre representación y conducta objetiva- puede llevar a afirmar necesariamente que existe dolo en aquellas situaciones en las que ha existido una representación inicial de un riesgo que ha sido eliminada mentalmente de forma voluntaria por el sujeto, en su confianza -más o menos fundada- de que todo acabaría bien: aceptar que para el dolo basta con representaciones o propósitos anteriores en el tiempo a la conducta inequívocamente típica entraña el riesgo de una importante ampliación del alcance de lo doloso a situaciones en las que, seguramente, nadie advertiría la necesidad de castigo propia del dolo. 
A modo de contrarréplica: la ignorancia deliberada y su difícil encaje ...

\section{I.4. Conclusión}

En resumen: si bien coincido con los autores citados en que gran parte de los supuestos que suelen tratarse por los tribunales españoles en el marco de la doctrina de la ignorancia deliberada son en realidad de dolo eventual, siguen presentándose casos -los de ignorancia deliberada en sentido estricto- para los que la doctrina tradicional sobre el tipo subjetivo no parece tener una solución adecuada y su equiparación al dolo solo es posible con una flexibilización extrema de los elementos que integran esta figura o la disociación temporal entre tipo objetivo y subjetivo, con todos los riesgos que ello comporta de desbordamiento del ámbito de lo doloso. Por tal motivo, la vía que parece más adecuada pasa por buscar un tratamiento específico para estas situaciones, lo que obliga a retomar la pregunta de con qué condiciones las situaciones de ignorancia deliberada merecen ser tratadas como supuestos de dolo.

\section{III. ¿Merece ser tratada la ignorancia deliberada como el dolo?}

\section{III.1. De nuevo: sobre el distinto tratamiento de dolo y culpa en lo que respecta a las consecuencias jurídicas}

Para responder a la pregunta sobre el tratamiento que merece la ignorancia deliberada (en sentido estricto) es necesario partir de una determinada concepción acerca de cuáles son las razones que explican el distinto tratamiento entre dolo y culpa en lo que respecta a las consecuencias jurídicas previstas para ambas formas de imputación subjetiva. Esta cuestión inicial resulta básica para abordar la presente materia y respecto de ella cabe defender opiniones diversas, como se advierte en el debate doctrinal de los últimos años (cfr. el resumen ofrecido en el texto inicial supra V.1). y también en los anteriores cuatro trabajos, en que los autores que se pronuncian sobre la cuestión se posicionan entre una justificación basada estrictamente en el distinto contenido expresivo existente entre el hecho doloso y el imprudente 
(Feijoo) o en la mayor peligrosidad para los bienes que concurre en el actuar doloso por el dominio que tiene el sujeto sobre su conducta y en la mayor responsabilidad del sujeto (Greco).

De entrada cabe señalar que el argumento de la peligrosidad no puede compartirse. Así, sostiene Greco que los hechos dolosos deben castigarse con mayor pena -o castigarse exclusivamente dejando impune la imprudencia en la mayoría de delitos- porque, al ser el comportamiento doloso más peligroso para los bienes jurídicos, desde una perspectiva consecuencialista es conveniente que el legislador destine prioritariamente sus recursos a prevenir tales actuaciones. Sin embargo, sostener tal opinión parece muy difícil cuando, por ejemplo, en circunstancias normales el número de personas fallecidas por accidente en cualquier país supera ampliamente al de las víctimas de asesinatos. Si de lo que se trata es de salvar bienes jurídicos ¿no tendría acaso sentido sancionar con mayor gravedad el homicidio imprudente? Por otra parte, la adaptación a las circunstancias fácticas que, según Greco, caracteriza al autor doloso y hace más peligrosa su actuación es por supuesto incuestionable, pero solo si se trata de un mayor riesgo que se manifiesta en el plano objetivo: ante peligros objetivos absolutamente idénticos el cambio en el tipo subjetivo (conocimiento o desconocimiento) no aporta una mayor peligrosidad al hecho. Finalmente, la idea de que el sujeto doloso es más responsable en tanto que ha obrado con mayor libertad puede seguramente compartirse porque es una afirmación que se corresponde con las precomprensiones más elementales sobre la noción de responsabilidad -la "intuición general" de la que habla Alberto Puppo (I)- pero de tal afirmación no se infieren sin más criterios que justifiquen el quantum de la pena si a ésta se le atribuye una función preventiva.

En el texto inicial (cfr. V) se han apuntado las razones que se consideraba que tenían mayor capacidad explicativa del distinto tratamiento punitivo entre estos dos modalidades delictivas, en concreto, la mayor indiferencia que muestra el autor doloso respecto del interés lesionado; y la pretensión de provocar con la pena el fracaso del delincuente doloso para evitar actos de imitación. Se trata de un planteamiento que acepta el factor expresivo como elemento básico, pero que 
A modo de contrarréplica: la ignorancia deliberada y su difícil encaje ...

lo complementa con un elemento de tipo preventivo-disuasorio que, entre otras razones, resulta necesario para explicar que la pena no sea un puro acto de desautorización sino que esté también dotada de un contenido material aflictivo. Como ya se ha adelantado en las páginas iniciales, dicha perspectiva se basa en una premisa -que aquí solo se esboza- según la cual la pena dirige un doble mensaje a todas las personas en su doble faz de ciudadanos que esperan ser protegidos por el Derecho y, al mismo tiempo, de infractores en potencia. En los casos de dolo directo, como supuestos paradigmáticos de dolo, el autor muestra una gran indiferencia (o incluso hostilidad) hacia el bien que lesiona y, además, en los supuestos consumados de intención consigue por regla general sus objetivos, lo que aconseja que la pena se imponga en su máxima intensidad para reafirmar el valor negado y evitar actos de imitación; por el contrario, el grado de indiferencia mostrado por parte de quien lesiona un interés ajeno por culpa inconsciente es mucho menor $\mathrm{y}$, además, el sujeto está expuesto a un elevado riesgo de fracaso en su planificación vital que hace que sean impensables actos de imitación por parte de terceros. Entre estos dos modelos extremos se da una transición gradual en la que se sitúan las restantes modalidades de dolo y culpa ... y también, cabe añadir, los casos de ignorancia deliberada en sentido estricto.

Obviamente el dolo y la imprudencia, en tanto que títulos de imputación, están diseñados partiendo de modelos ideales configurados a partir de determinadas características genéricas, que en el caso concreto puede presentarse de manera más o menos perfecta o intensa, lo que sin duda requerirá que en ciertos casos se produzcan algunos ajustes en la determinación de la pena si la ley lo permite. Respondiendo a algunas objeciones planteadas: por supuesto también el delincuente doloso puede padecer pena natural (por ejemplo, el terrorista gravemente herido por la onda expansiva de su propia bomba homicida), del mismo modo que, excepcionalmente, el delincuente imprudente puede conseguir alguno de sus objetivos (como sucede en el caso clásico de dolus subsequens, en el que un sujeto atropella por descuido a un peatón desconocido que, casualmente, descubre a posteriori que se trataba de su peor enemigo, al que tenía proyectado asesinar la semana siguiente). Sin embargo, y 
dejando de lado estos casos poco o nada frecuentes, lo que suele suceder en la práctica es que el delincuente doloso, a diferencia del imprudente, se abre camino con la realización efectiva de una determinada planificación vital entendida en sentido amplio, es decir, como mayor probabilidad de consecución tanto de los propósitos estrictamente típicos (como la producción del resultado en los tipos que lo requieran) como extratípicos (obtención de impunidad, por ejemplo). Quien sabe lo que hace tiene mayores probabilidades de realizar sus propósitos que quien obra sin saber lo que está haciendo y es lógico que exista una mayor riesgo de actos de imitación del primero que del segundo.

\section{III.2. Sobre la respuesta jurídica adecuada en los casos de ig- norancia deliberada en sentido estricto}

¿A cuál de estos dos modelos ideales se parecen más los casos de ignorancia deliberada en sentido estricto? Desde luego, casos como el del usuario de correo electrónico descritos al inicio de estas páginas parecen estar mucho más cercanos a los supuestos de intención que a los de descuido inconsciente. Puede discutirse si quien envía a la lista de "correo basura" todas las notificaciones oficiales que recibe muestra más o menos indiferencia respecto del correcto funcionamiento de las administraciones públicas que quien decide romper sin leer una notificación oficial. Pero, en todo caso, se trata de un grado de indiferencia muy superior al del sujeto olvidadizo que no atiende a un requerimiento judicial porque durante meses olvida revisar el buzón. Y, por otra parte, es evidente que el primero logra calculadamente sus objetivos, pues no solo no cumplirá con su obligación legal sino que, además, si llega a ser procesado podrá aportar pruebas fehacientes de que el concreto requerimiento nunca llegó a ingresar en la bandeja de entrada de su programa de correo electrónico y, por consiguiente, nunca tuvo un correcto conocimiento de su contenido.

Como ya se expuso en el texto inicial (V.2), afirmar en casos como el anterior la concurrencia de una situación de error o de descuido no solo parece cuestionable respecto de las consecuencias jurídicas que comporta tal afirmación, sino que parece oponerse al propio uso cotidiano del lenguaje: 
A modo de contrarréplica: la ignorancia deliberada y su difícil encaje ...

nadie diría que el sujeto que ha configurado el servidor de correo de tal modo que todas las notificaciones oficiales vayan a la lista de "correo basura" se ha equivocado al no leer los mensajes o es una persona descuidada. Por otra parte, impedir que el sujeto alegue en su favor un estado de ignorancia que le es imputable en modo alguno parece contradecir algunos de los principios básicos de la teoría de la imputación jurídico-penal, sino al contrario: existen razones de peso para sostener, partiendo del propio Derecho positivo, que rige en Derecho penal un principio según el cual nadie puede invocar en su descargo la concurrencia de un contexto de exoneración que él mismo ha contribuido a generar con el objeto de eludir la norma, como sucede con los supuestos abarcados por la ya mencionada teoría de la actio libera in causa, o con la imposibilidad de aplicar causas de justificación como la legítima defensa o el estado de necesidad a quien ha provocado, respectivamente, la agresión ilegítima o la situación de necesidad. ¿Por qué no habría de tener su concreción este principio general -que tiene vínculos evidentes con la figura del fraude de ley- en lo que respecta al tipo subjetivo?

La cuestión a responder en todo caso en lo que respecta al tipo subjetivo es qué cabe entender por haber generado de manera imputable un contexto de exoneración con el objeto de eludir la norma. En este último sentido conviene no perder de vista, como ya se ha adelantado, que la decisión consciente de mantenerse en un estado de desconocimiento se presenta igualmente en situaciones en las que no parece que concurran las razones que justifican el tratamiento penológico agravado del dolo. También permanece en una situación de desconocimiento deliberado el cargo público que, por ejemplo, firma cientos de resoluciones que le han preparado sus subordinados sin repasar uno por uno los correspondientes expedientes; o el magistrado miembro de un tribunal que vota en un determinado sentido sin revisar personalmente los autos al confiar en el resumen del caso que le ofrece el magistrado ponente. ¿Cabría en tales supuestos sostener, en caso de ser engañados, que concurre una prevaricación que merece ser tratada como dolosa?

Todo indica que la respuesta a dicha cuestión debe ser negativa, lo que probablemente se explica porque el grado de indiferencia 
mostrado hacia el interés lesionado y la circunstancia de que el sujeto no decidiera permanecer en la ignorancia como medio para esgrimir a su favor una eximente impiden sostener tal equiparación. De ahí que seguramente deba restringirse notablemente la equiparación entre el dolo y ciertos casos de ignorancia deliberada y limitarlos a aquellas situaciones en las que concurran los dos elementos siguientes: 1) Que el sujeto haya obrado en la sospecha de estar llevando a cabo una acción u omisión potencialmente lesiva en el futuro para algún interés indeterminado; y 2) Que haya permanecido en la ignorancia con el propósito de "construirse" una excusa que le exonere en el supuesto de acabar produciéndose tal lesión. E1 primer elemento incorpora el factor de indiferencia cualificada que, como se ha dicho, exige el tratamiento punitivo agravado del dolo respecto de la culpa; y el segundo toma en cuenta la necesidad-acentuada en los casos de dolo- de provocar con la pena el fracaso del sujeto infractor. Este último elemento, conviene precisar, no solo consiste en la mera intención de no profundizar en la sospecha inicial -algo que sucede también en casos anteriormente citados, como el del juez o el conductor de autobús- sino en una especial motivación: la voluntad de construirse una excusa que podrá esgrimir cuando se le exija responsabilidad.

En todo caso conviene señalar que la adición de este elemento de tipo intencional o, si se prefiere, motivacional aporta una capacidad delimitadora del alcance de la doctrina que conviene tener presente. Se trata, en palabras de la STS 234/2012, citada por el propio Feijoo, de "un componente motivacional, inspirado en el propósito de beneficiarse del estado de ignorancia alentado por el propio interesado, eludiendo así la asunción de los riesgos inherentes a una eventual exigencia de responsabilidad penal". La exigencia de este elemento permite superar críticas como la formulada en su trabajo por Laura Manrique, cuando señala (II.b) que la mera apelación a la indiferencia no permite diferenciar bien la imprudencia del dolo por cuanto, según la concepción aquí defendida, es un elemento común a ambos. Aun cuando, como ya se ha expuesto, el grado de indiferencia exigido en uno y otro caso es cuantitativamente diferente, la adición de este elemento motivacional añade una diferencia de carácter cualitativo y, como exige la propia autora (ibídem), 
A modo de contrarréplica: la ignorancia deliberada y su difícil encaje ...

incorpora un elemento que toma en consideración las razones por las que actuó el sujeto. En cierto modo, cabe precisar, los déficits cognitivos que se presentan en estas situaciones se ven compensadas por el componente motivacional.

Esta capacidad de contener el riesgo de desbordamiento de la doctrina de la ignorancia deliberada puede advertirse con algunos ejemplos concretos: así, es dudoso que en algunos de los casos citados por Feijoo (casos del transporte de la bomba o de armas bioquímicas I.3), Puppo (caso del inmigrante ilegal III.1.A) o Manrique (caso del ocultamiento del bebé II.a) los sujetos activos hayan procurado evitar ciertos conocimientos como una forma de preconstituirse una alegación de descargo en caso de imputación penal. En tal sentido, los ejemplos no coinciden con el caso reiteradamente citado del correo electrónico o del testaferro profesional en los que sí puede afirmarse que el sujeto ha pretendido permanecer al margen de cierta información para poder conseguir sus objetivos ilícitos (desobedecer requerimientos judiciales, administrar formalmente sociedades a cambio de dinero) preparándose una excusa ("yo no sabía") para el caso en que alguien les exija responsabilidad por ello. En todo caso, y como no podría ser de otro modo, deberán ser las acusaciones quienes prueben la concurrencia de este elemento adicional y, en caso de apreciarlo, el juez deberá exponer sus razones en la sentencia, quedando así salvadas los comprensibles recelos acerca del respeto a la presunción de inocencia que expone Feijoo en su trabajo (I.3).

\section{III.3. Respuestas a cuestiones particulares}

Sentadas las anteriores premisas, procede seguidamente dar respuesta a algunos de los comentarios formulados por los cuatro autores en sus respectivos trabajos:

1. La necesidad de que el sujeto haya buscado no profundizar en sus sospechas iniciales como una estrategia para exculparse en caso de ser descubierto no se opone a que dicho individuo pueda obrar guiado por otros propósitos y que alguno de estos propósitos, como 
señala Puppo (III.B), pueda no merecer una valoración negativa sino todo lo contrario. Volviendo al ejemplo del testaferro profesional cabe imaginar, por ejemplo, que el hombre de paja pretenda destinar la retribución obtenida con el cargo de administrador formal, a obras de caridad. Sin embargo, la teoría del delito ya cuenta con otros elementos como la antijuricidad o la culpabilidad donde, si procede, pueden tenerse en cuenta tales factores: nadie cuestiona que quien intencionadamente se apodera a punta de pistola de las joyas ajenas obra dolosamente con independencia de lo que haga con ellas posteriormente (tal vez ayudar a su madre enferma comprándole medicamentos, por retomar el ejemplo propuesto por Puppo), pues para el dolo basta con que el menoscabo del interés protegido haya sido abarcado con el conocimiento y, según la modalidad aplicable, también la intención. Del mismo modo, para la ignorancia deliberada debería bastar con constatar que el sujeto ha decidido no profundizar en sus vagas sospechas con el propósito de procurarse una alegación exculpatoria en caso de ser descubierto, sin que sean relevantes a los efectos de la imputación subjetiva ulteriores propósitos que puedan explicar semejante decisión.

Por ello debe darse la razón a Greco cuando afirma que puede existir dolo altruista y culpa egoísta, del mismo modo que la ignorancia deliberada puede también presentarse en casos de concurrencia de motivaciones adicionales a la de preconstituirse una eximente, motivaciones ulteriores que, consideradas en abstracto, son susceptibles de una valoración de muy diverso signo. La teoría jurídico-penal de la imputación subjetiva no consiste en indagar a la hora de determinar la responsabilidad de un sujeto cuáles han sido todas aquellas razones, motivos o propósitos que puedan haber guiado su actuación, sino en determinar primero qué concretos motivos son relevantes para la atribución de responsabilidad penal (decisión normativa) y seguidamente ver en el juicio de subsunción fáctica si en el caso concreto concurren tales motivos.

En consecuencia -y replicando a Puppo (III.A.1)- la aceptabilidad moral última de las razones que mueven al sujeto es algo que ciertamente puede interesar a la teoría del delito (y que es especialmente 
A modo de contrarréplica: la ignorancia deliberada y su difícil encaje ...

importante en concretas figuras delictivas o circunstancias agravantes que exigen una motivación especial), pero que es intrascendente para la teoría del tipo subjetivo, a la que solo preocupa si entre los propósitos del sujeto estuvo la causación del resultado lesivo (dolo directo de primer grado como modalidad de dolo) o procurarse una excusa para el caso de lesión (ignorancia deliberada), sin necesidad de mirar más allá. En consecuencia no se trata de valorar la reprochabilidad moral del sujeto en cuanto tal, sino solo de reprocharle moralmente la realización de un hecho con determinadas características objetivas y subjetivas así como las consecuencias negativas que tal realización entraña. En tal sentido, la aceptación de que ciertos casos de ignorancia deliberada merecen la misma respuesta que supuestos de dolo no debería entrañar ningún riesgo de menoscabo para la vigencia del principio de responsabilidad por el hecho.

2. Otra crítica a considerar es la que formula Feijoo (I.3.) acerca del posible "versarismo" de la teoría de la ignorancia deliberada. Desde su punto de vista, según esta teoría una vez tomada la decisión de no profundizar en ciertas sospechas, se imputaría subjetivamente al individuo cualquier resultado lesivo que pudiera llegar a producirse en el plano objetivo. Se trata de una crítica a tener muy en cuenta si bien -conviene advertirlo- puede extenderse también al concepto hiperflexible de dolo eventual alternativo que el propio autor defiende en páginas anteriores. En tal sentido es evidente que la actitud que muestra frente al interés lesionado quien sabe -o sospecha de manera fundada y concreta que lo está lesionando- es distinta que la de quien prefiere inhibirse y no llegar a conocer siquiera el interés que puede llegar a lesionar aun en la conciencia de que se acción u omisión es potencialmente lesiva para diversos intereses. Por volver al ejemplo del testaferro, la actitud ante el patrimonio ajeno que muestra con su comportamiento quien se presta a administrar formalmente una empresa a sabiendas de que será utilizada para cometer una estafa no es igual que la de quien se representa que los cientos de empresas administradas serán tal vez algún día empleadas para cometer algún fraude a algún patrimonio público o privado. El hecho de que en el 
primer caso se llegue a concretar el interés lesionado y en el segundo tal interés quede en una situación inconcreta tal vez justifique que el grado de indiferencia mostrado en el segundo caso sea inferior, pero en todo caso se trata de una diferencia cuantitativa, no cualitativa, como la que el propio Feijoo reconoce (I.3 y III) cuando afirma que "la imprudencia es también indiferencia con respecto al bien jurídico, solo que a través de la norma de cuidado".

Sin embargo, los casos que especialmente preocupan a Feijoo son aquellos en los que la consecuencia objetiva resultaba totalmente inesperada. Un supuesto en tal sentido podría ser, por ejemplo, el del testaferro que se encuentra con que la sociedad que se prestó a administrar ha sido empleada no para cometer los delitos más frecuentes -insolvencias, fraudes fiscales, estafas, tráfico de drogas etc- sino delitos mucho más graves e infrecuentes: por ejemplo, relacionados con el terrorismo si la sociedad es empleada para financiar a una organización de tal naturaleza. Condenar en tal caso por cooperación con organización terrorista por la simple decisión de no querer profundizar en los detalles de una determinada sociedad de las decenas de centenares de sociedades que administra el testaferro puede parecer desproporcionado por exceso. Pero, a la vez, puede parecer también desproporcionado por defecto tratar a este sujeto de igual manera -es decir, con la impunidad- que a quien ha sido engañado eficazmente por una persona de confianza para que se prestara a administrar la sociedad. Tal vez la consecuencia de ello sea que la indiferencia mostrada en el ejemplo citado hacia los intereses lesionados con los actos terroristas no sea tan grave como la de quien actúa con dolo directo. Pero deberá convenirse que, en todo caso, parece más grave que la del sujeto que ha confiado en que no se emplearía la sociedad en nada ilegal.

3. Por último, conviene dar una breve respuesta a una objeción planteada por Luis Greco, concretamente la que señala que, si se equipara la ceguera intencionada al dolo, también deberán ser punibles aquellos casos de realización incompleta o, en otras palabras, de tentativa realizada en ignorancia deliberada. Desde luego, tiene toda la razón Greco cuando afirma que, si se equipara la ignorancia deliberada al 
A modo de contrarréplica: la ignorancia deliberada y su difícil encaje ...

dolo, en rigor en el caso Jewell (el sujeto que transportó drogas a través de la frontera mexicana) el acusado debería ser castigado por tantas tentativas como objetos ilícitos pudo imaginar estar transportando. Sin embargo, éste no es un problema exclusivo de la teoría de la ignorancia deliberada, sino de la teoría del dolo eventual en general: el mismo problema se plantea en el caso del sujeto que recibe una maleta para que la transporte a cambio de dinero y se representa el riesgo de que pueda contener drogas, dinero, armas o tal vez pornografía infantil. Si finalmente resulta que la maleta contiene solamente libros ¿deberá condenarse al sujeto por cuatro tentativas inidóneas con dolo eventual de los correspondientes delitos? No cabe duda de que la cuestión de si debe castigarse la tentativa (inidónea) con dolo eventual es especialmente espinosa y que las dudas que plantea esta cuestión se extienden también a la ignorancia deliberada si se admite la equiparación de otras figuras. En todo caso, la solución al problema no parece que deba consistir en rechazar la equiparación en algunos casos la equiparación entre ambas, sino que pasa por otras vías que permitan, en general, superar el problema de la tentativa en casos que no son de dolo directo, como la exigencia de intención para que la tentativa sea punible o, de lege ferenda, la previsión de un sistema de numerus clausus para la punición de modalidades intentadas en las que falte el propósito específico de consumar.

\section{IV. ¿Existen problemas de lege lata para equiparar la ig- norancia deliberada al dolo?}

En algunos de los cuatro trabajos previos se cuestiona que la equiparación de ciertas formas de ignorancia deliberada con el dolo eventual sea compatible con el texto de la ley. A mi juicio para dar respuesta a tales cuestiones cabe distinguir entre dos situaciones posibles:

a) En el caso de aquellos ordenamientos que contienen una definición legal de dolo -tal sería el caso, por ejemplo, de países como Colombia o Italia (como se señala en el texto de Puppo)- que exija expresamente conocimiento, el texto de la ley impide dar entrada a los casos de igno- 
rancia deliberada en el concepto de dolo. Parece claro que entender que casos de ignorancia son subsumibles en términos legales como "previsión", "conocimiento" o "representación" resulta imposible sin violentar el principio de legalidad. Sin embargo, el que en tales supuestos la autoridad de la ley imponga como correcta una solución no zanja el debate sobre si hay casos de ignorancia deliberada que merecen la misma pena que el dolo eventual; $y$, si se responde afirmativamente a tal cuestión, entonces el texto de la ley es parte del problema y no de la solución, como sucede en todos aquellos casos en los que el legislador impone una definición legal de los principales conceptos de la teoría del delito y la discusión académica pone en evidencia que existen supuestos que no están correctamente abarcados por el texto legal pese a que merecerían estar incluidos en él. Algo parecido cabe afirmar de aquellos casos, que pueden plantearse en ordenamientos, que no necesariamente contengan una definición legal de dolo, en los que algunos tipos penales incluyen exigencias concretas de naturaleza subjetiva, tales como que el sujeto obre "a sabiendas" o "con conocimiento" de un determinado elemento del tipo objetivo.

b) Más dudas suscita, en cambio, la afirmación de que en aquellos países que carecen de un concepto de dolo el obstáculo legal insalvable radicaría en la regulación del error de tipo (opinión que se sostiene por los cuatro autores del presente volumen). Y ello es así porque, como se ha expuesto supra, cabe discutir que se encuentre en una situación de error aquél que no quiere conocer una determinada realidad: como sostienen algunas voces en la doctrina, solo yerra aquel que tiene interés en conocer, de tal modo que quien busca permanecer en la ignorancia no incurre en error alguno ${ }^{13}$. Puede discutirse el acierto o no de este planteamiento: pero en todo caso si se excluyen del concepto legal de error los casos de desconocimiento provocado no parece en

${ }^{13}$ En tal sentido, tajante, JAKOBS, "Indiferencia como dolo indirecto", trad. C. Pérez del Valle, en López Barja de Quiroga / Zugaldía Espinar (coords.), Dogmática y ley penal. Libro homenaje a Enrique Bacigalupo, tomo I, Madrid-Barcelona, 2004, p. 349: " ¡Es tan obvio que no todo desconocimiento es un error!". 
A modo de contrarréplica: la ignorancia deliberada y su difícil encaje ...

modo alguno que se esté incurriendo en una vulneración del principio de legalidad. No desde luego en Derecho español, pues en el art. 14 del Código penal aparece la palabra "error" pero, a diferencia de lo que sucede en el Código alemán ( $(16)$, brillan por su ausencia expresiones como "conocimiento" o "representación". No se quiere negar aquí la afirmación de Manrique cuando señala (III.b) que "aun cuando no existan definiciones expresas los jueces están comprometidos a usar las palabras de la ley en el mismo sentido en que las ha usado el legislador". Sin embargo, ¿puede realmente entenderse que el legislador ha utilizado el término imprudencia en el sentido de incluir en este término los casos aquí descritos que en modo alguno responden al modelo del sujeto negligente?

Por tal motivo, no puede compartirse la opinión de Feijoo (I.3) cuando argumenta que "sostener de lege data que no existe un error allí donde el sujeto no quería o no estaba interesado en saber y, por lo tanto, es responsable de su desconocimiento es una normativización contra legem". Una afirmación de la que debe discreparse no solo porque esté en discusión la legitimidad de realizar reducciones teleológicas en aquellos elementos que excluyen la responsabilidad ${ }^{14}$,

${ }^{14}$ La doctrina es muy estricta con la prohibición de la analogía in malam partem cuando supone la ampliación de la prohibición más allá de los límites gramaticales del tipo penal, pero parece ser en cambio más tolerante con aquellas reducciones teleológicas que suponen la limitación del alcance de una determinada causa de exención de responsabilidad penal, como puede ser, por ejemplo, la legítima defensa -a la que se aplican sin base legal alguna en algunos países las llamadas "restricciones ético-sociales"-o el desistimiento voluntario, en el que mayoritariamente se interpreta que la voluntariedad debe negarse cuando concurren determinadas motivaciones aun cuando el sujeto haya tenido la posibilidad física de consumar el delito. Cfr. al respecto SiLva SÁnchez, "Sobre la 'interpretación' teleológica en Derecho Penal", en Díaz y GarCíAConlledo / García Amado (coords.), Estudios de Filosofía del Derecho Penal, 2006, pp. 378-379, quien pone de manifiesto cómo, sin un criterio claro, el Tribunal Supremo español acude a las reducciones teleológicas en unos casos -además de los casos citados supra, por ejemplo, en la atenuante de confesión- y, sin embargo las rechaza en otros. En la doctrina alemana, sin ir más lejos, Roxin, Strafrecht. Allgemeiner Teil. Vol. I: „Grundlagen Der Aufbau der Verbrechenslehre“, $4 .^{\mathrm{a}}{ }^{\mathrm{e}}$ ed., Múnich, 2006., $§ 5$ n. ${ }^{\circ}$ marg. 42 y § 15 n. ${ }^{\circ}$ marg. 52, señala tajantemente que el límite del tenor literal no rige en absoluto en las cau- 
sino porque cabe discutir incluso que tengan cabida en el tenor literal de la expresión "error" los casos de quienes buscan permanecer en el desconocimiento. ¿Realmente el sujeto del reiterado ejemplo del correo electrónico puede alegar en su descargo "no me di cuenta" o "me equivoqué" cuando se le pregunté por qué no respondió el requerimiento judicial recibido?

\section{Consideraciones finales}

Pese a las discrepancias observadas en los previos trabajos cabe constatar algunos puntos de significativa coincidencia. Entre ellos destaca el acuerdo existente con algunos autores en la necesidad de enriquecer el sistema legal vigente de imputación subjetiva más allá de la distinción binaria entre dolo e imprudencia (Manrique I), creando por ejemplo, y en palabras de Bernardo Feijoo, "una categoría intermedia de imprudencia grosera o grave desconsideración" (II.1). Una propuesta muy razonable -como se apuntaba ya en el texto inicial (V.2) - si bien debería ir acompañada de la exigencia de que entre estos diversos títulos de imputación subjetiva no se dieran los importantes saltos penológicos que se advierten a menudo en la actualidad. Ello invita a pensar, como otra opción posible, en si acaso no sería mejor optar por un modelo que no distinguiera entre títulos de imputación subjetiva y delegara en el juez la concreción penológica que en cada supuesto concreto mereciera el grado de indiferencia mostrado por el sujeto respecto del interés lesionado y otras circunstancias relevantes, precisando en todo caso a propósito de delitos concretos determinadas exigencias subjetivas mínimas.

Cuál debe ser el diseño de un sistema de imputación subjetiva que permita superar los problemas que plantea el vigente es uno de los retos más apasionantes que la ciencia penal tiene por delante, una tarea que no debería postergarse por el hecho de contar con ciertos obstáculos -más o menos intensos- en el texto de la regulación legal vigente: el objetivo de la ciencia penal debe ser adaptar la ley al criterio que se considera 
A modo de contrarréplica: la ignorancia deliberada y su difícil encaje ...

más justo sin renunciar a tal tarea por el hecho de que en un determinado momento y lugar el Derecho vigente parezca acoger una solución distinta. Las piezas que no encajan en el sistema -como sucede con algunos casos de ignorancia deliberada- no deben ser vistas con incomodidad, sino como una señal de aviso de que muy posiblemente algunas de las premisas en las que dicho sistema se ha basado tradicionalmente merecen ser repensadas. 